\title{
AVALIAÇÃO DO EFEITO DAS VARIÁVEIS DE PROCESSO NA OBTENÇÃO DO ÓLEO DE SEMENTES DE CHIA POR EXTRAÇÃO ASSISTIDA POR ULTRASSOM
}

\author{
B. T. F. MELLO ${ }^{1}$, P. J. SILVA ${ }^{1}$ e C. SILVA $^{1}$ \\ ${ }^{1}$ Universidade Estadual de Maringá, Departamento de Tecnologia \\ E-mail para contato: camiladasilva.eq@gmail.com
}

RESUMO - O presente trabalho teve como objetivo avaliar o efeito das variáveis de processo na condução da extração assistida por ultrassom do óleo de sementes de chia, bem como o perfil de ácidos graxos do extrato obtido. Os experimentos avaliam diferentes solventes para extração, sendo que os rendimentos obtidos com $n$-hexano e acetato de etila não apresentam diferenças significativas $(p>0,05)$. Na avaliação do efeito das variáveis de processo os resultados obtidos, com acetato de etila como solvente, relatam que a quantidade de solvente utilizado da extração apresenta-se como a variável com maior efeito significativo $(\mathrm{p}<0,05)$, dentro da faixa experimental avaliada, seguida da temperatura. $\mathrm{O}$ maior rendimento em óleo foi obtido em $60^{\circ} \mathrm{C}, 40$ minutos de extração e razão massa de sementes: volume de solvente 1:12. O perfil de ácidos graxos do extrato reporta predominância do ácido linolênico, sendo que o mesmo apresenta similar aos extratos obtidos por outros métodos de extração.

\section{INTRODUÇÃO}

Nos últimos anos as sementes de chia foram incluídas na dieta humana devido a sua importante composição e os benefícios que o seu consumo traz à saúde (Ixtaina et al., 2011; Capitani et al., 2012). De acordo com Ixtaina et al. (2011), a chia tem sido investigada e recomendada para o consumo, devido ao seu elevado percentual de ácidos graxos benéficos para saúde, proteínas, compostos antioxidantes e fibras alimentares. A literatura relata a adição de chia na formulação de diversos produtos alimentícios (Maruyama et al., 2013, Pizarro et al., 2013).

De acordo com Borneo et al. (2010) de $25 \%$ a $35 \%$ da composição da chia é óleo, principalmente ácidos graxos essenciais (ácido linoleico e linolênico), além de $\sim 22 \%$ de fibras e $\sim 24 \%$ de proteínas. Ayerza (1995) e Dauksas et al. (2002) reportam que o óleo de sementes de chia é um produto com composição química variável, dependendo de vários fatores como o ambiente de cultivo e o sistema de extração. Capitani et al. (2012) relataram que a preparação da matéria-prima e diferentes tipos de solventes utilizados para extração do óleo podem afetar de forma diferente o seu conteúdo. Martínez et al. (2012) relataram que um dos principais objetivos na produção do óleo de chia é encontrar um método adequado para preservar a qualidade do óleo.

A extração assistida por ultrassom é considerada um método não convencional que vem demonstrando eficiência na extração de compostos bioativos, trazendo vantagens relacionadas ao menor consumo de solventes, baixos tempos de extração e elevados rendimentos de extração quando comparado aos métodos tradicionais (Chemat et al., 2011; Vilkhu et al., 2008). A presente técnica de extração é fundamentada no fenômeno de cavitação (Esclapez et al., 2011), que 
ocasiona a formação de cavidades, para onde os gases dissolvidos no sistema migram, formando microbolhas, que aumentam e diminuem de tamanho, gerando ciclos de expansão e compressão até que as bolhas implodem, liberando grande quantidade de calor e exercendo elevadas pressões próximas a região da implosão (Cárcel et al., 2012). Essas colisões fazem com que células vegetais sejam rompidas, facilitando a difusão do solvente extrator para o interior da matriz (Patist e Bates, 2008), melhorando a transferência de massa. Somando-se a isso, o calor liberado pelas implosões aumenta a solubilidade dos analitos, favorecendo o aumento da eficiência da extração. Assim, é possível ao mesmo tempo agitar a mistura e extrair os compostos em um tempo muito mais curto que aqueles utilizados pelos métodos tradicionais de extração, utilizando uma quantidade pequena de solventes (Chemat et al., 2011; Vilkhu et al., 2008).

Aliado à eficiência da técnica de extração, tem-se recentemente com o desenvolvimento dos conceitos de química verde (Prado, 2003), a pesquisa da eficiência da utilização de solventes menos agressivos ao meio ambiente e que apresentem aceitáveis rendimentos quando utilizados em baixas quantidades. Sendo que o óleo de chia é utilizado principalmente como alimento, estes solventes devem ser aceitáveis pela indústria alimentícia.

Neste contexto, o objetivo do presente trabalho foi investigar a extração assistida por ultrassom do óleo de sementes de chia e avaliação da eficiência de diferentes solventes na extração. Os experimentos foram conduzidos em um banho de ultrassom e avaliaram o efeito das variáveis operacionais (temperatura, tempo e volume de solvente) no rendimento em óleo, adotando um planejamento Box-Behnken.

\section{MATERIAIS E MÉTODOS}

\subsection{Materiais}

As sementes de Salvia hispanica L. foram obtidas no mercado local de Umuarama (PR, Brazil). As sementes de chia apresentam composição centesimal das sementes de: 7,82 $\pm 0,06$ de umidade, 4,77 $\pm 0,09$ de cinzas, $18,65 \pm 0,06$ de proteína, 35,80 $\pm 0,15$ de lipídeos e 22,78 $\pm 0,98$ de fibra bruta, determinada de acordo com IAL (2008). As sementes foram trituradas em moinho elétrico (Marconi) e classificadas usando peneiras da série Tyler (Bertel, ASTM) para produzir partículas com diâmetro médio de $0,3585 \mathrm{~mm}$. Para as extrações foram utilizados os solventes: acetato de etila (F Maia), $n$-hexano (F Maia) e isopropanol (JT Baker). Todos os solventes e reagentes utilizados neste estudo foram de grau analítico. O padrão heptadecanoato de metila ( $>99 \%$ de pureza) e derivatizante $\mathrm{BF}_{3}-$ metanol foram obtidos da Sigma-Aldrich Chemical Co.

\section{2. Extração Assistida por Ultrassom}

A extração das sementes de chia foi realizada em banho de ultrassom (Ultronique, Q 5.9/40A), onde $5 \mathrm{~g}$ de sementes foram colocadas em Erlenmeyer com tampa de vidro (250 $\mathrm{mL})$ juntamente com os solventes, mantendo-se a proporção amostra-solvente estabelecida no planejamento experimental. O Erlenmeyer foi conectado a um condensador ligado a um banho refrigerado (Marconi, MA 184) e submetido ao tratamento em banho indireto de ultrassom na temperatura e durante o tempo estabelecido no planejamento experimental. Após o período de extração as amostras foram filtradas e o excesso de solvente, no filtrado, foi evaporado em rota evaporador (Marconi, MA120) e o remanescente mantido em estufa até peso constante. Os extratos foram armazenados sob refrigeração até a realização das análises, as quais foram 
realizadas em duplicata. O rendimento foi calculado como a razão entre a massa extraída de óleo e a massa de polpa utilizada.

Primeiramente, avaliou-se a eficiência de diferentes solvente na extração do óleo de Chia, mantendo as variáveis temperatura, razão semente:solvente e tempo fixas. Para determinar a influência dos fatores principais sobre o rendimento da extração foram testados três níveis das variáveis, temperatura $\left(40,50\right.$ e $\left.60{ }^{\circ} \mathrm{C}\right)$, tempo $(20,40$ e $60 \mathrm{~min})$ e razão semente: solvente $(1: 8$, 1:10 e 1:12), utilizando um planejamento Box-Behnken utilizando o solvente selecionado. O software Statistica 8.0 (STATSOFT TM, Inc) foi utilizado para a análise estatística dos dados, utilizando intervalo de $95 \%$ de confiança.

\subsection{Análise dos Ácidos Graxos}

Com a finalidade de determinar o perfil de ácidos graxos totais por cromatografia gasosa, foi realizada a derivatização do óleo com solução metanólica de $\mathrm{BF}_{3}$ seguindo a metodologia padrão AOAC Ce 2-66 (Walker, 1990). Posteriormente, as análises foram conduzidas em cromatógrafo a gás acoplado a espectro de massa (Thermo-Finnigan), utilizando uma coluna capilar Agilent HP-5MS (30 m x 0,250 mm x 0,25 $\mu \mathrm{m})$ e as condições utilizadas foram: injeção de $0,4 \mu \mathrm{L}$ no modo split $1: 10$, temperatura inicial da coluna de $120{ }^{\circ} \mathrm{C}$, mantida nesta temperatura por 5 minutos, aumentando para $180{ }^{\circ} \mathrm{C}$ à taxa de $15{ }^{\circ} \mathrm{C} \min ^{-1}$ e para $240{ }^{\circ} \mathrm{C}$ à $5{ }^{\circ} \mathrm{C} \min ^{-1}$, permanecendo por 5 minutos. A vazão do gás de arraste, hélio, foi de $1 \mathrm{~mL} \mathrm{~min}^{-1}$. A identificação dos componentes presentes nas amostras foi realizada pelo programa Xcalibur ${ }^{\mathbb{R}}$ (Thermo Electron) e para a quantificação dos ácidos graxos totais, heptadecanoato de metila foi utilizado como padrão interno.

\section{RESULTADOS E DISCUÇÕES}

\subsection{Eficiência de Diferentes Solventes}

Os resultados para rendimento em óleo obtidos para os diferentes solventes testados estão apresentados na Tabela 1, sendo estes resultados obtidos na temperatura de $40{ }^{\circ} \mathrm{C}$, razão semente:solvente de 1:8 e tempo de $30 \mathrm{~min}$. De acordo com a Tabela 1, os solventes com maior poder extrativo foram o $n$-hexano e acetato de etila com rendimentos de $26,51 \%$ e $25,92 \%$, respectivamente, sendo que não foi observada diferença significativa entre estes solventes ( $>0.05$ ). O isopropanol apresentou $22,96 \%$ de rendimento em óleo na condição avaliada.

Os resultados obtidos podem ser explicados em função da polaridade do solvente. O nhexano é um solvente não polar e o acetato de etila e isopropanol apresentam índice de polaridade de 4,4 e 3,9, respectivamente. Pode-se notar que o maior rendimento em óleo foi relatado com o uso de solvente apolar e solvente polar com elevado índice de polaridade. Oliveira et al. (2013) reportam baixos rendimentos para a extração assistida por ultrassom do óleo de sementes de maracujá utilizando os solventes etanol e isopropanol, quando comparado com os rendimentos obtidos com $n$-hexano. Considerando que não foi observada diferença significativa entre os resultados com acetato de etila e $n$-hexano $(p>0,05)$ e que o acetato de etila apresenta menor custo (Tian et al., 2013), este solvente mostra-se mais adequado para extração do óleo de sementes de chia. 
Tabela 1 - Resultados de rendimento em óleo na avaliação da eficiência de diferentes solventes.

\begin{tabular}{|c|c|}
\hline Solvente & Rendimento (\%) \\
\hline$n$-hexano & $26,51 \pm 0,16^{\mathrm{a}}$ \\
\hline Isopropanol & $22,96 \pm 0,66^{\mathrm{b}}$ \\
\hline Acetato de etila & $25,92 \pm 0,08^{\mathrm{a}}$ \\
\hline
\end{tabular}

\subsection{Efeito das Variáveis Operacionais}

A Tabela 3 apresenta as condições experimentais para o planejamento Box-Behnken, com 16 ensaios, bem como os resultados de rendimento em óleo nas condições avaliadas. $\mathrm{O}$ rendimento em óleo obtido foi de 18,95 a 27,03\%, sendo que os maiores rendimentos foram obtidos em $60^{\circ} \mathrm{C}, 40$ minutos de extração e razão massa de sementes: volume de solvente 1:12.

Tabela 3 - Condições experimentais e rendimento em óleo na avaliação do efeito das variáveis operacionais utilizando um planejamento Box-Behnken.

\begin{tabular}{|c|c|c|c|c|}
\hline Experimento & Tempo & Temperatura & $\begin{array}{c}\text { Razão } \\
\text { semente:solvente }\end{array}$ & Rendimento (\%) \\
\hline 1 & -1 & -1 & 0 & 21,26 \\
\hline 2 & 1 & -1 & 0 & 24,36 \\
\hline 3 & -1 & 1 & 0 & 25,50 \\
\hline 4 & 1 & 1 & 0 & 24,03 \\
\hline 5 & -1 & 0 & -1 & 18,95 \\
\hline 6 & 1 & 0 & -1 & 22,13 \\
\hline 7 & -1 & 0 & 1 & 25,62 \\
\hline 8 & 1 & 0 & 1 & 24,25 \\
\hline 9 & 0 & -1 & -1 & 22,74 \\
\hline 10 & 0 & 1 & -1 & 23,88 \\
\hline 11 & 0 & -1 & 1 & 26,18 \\
\hline 12 & 0 & 1 & 1 & 27,03 \\
\hline 13 & 0 & 0 & 0 & $26,78 \pm 0,38^{\mathrm{a}}$ \\
\hline
\end{tabular}

${ }^{a}$ média de quatro experimentos.

A Tabela 4 apresenta os efeitos das variáveis independentes sobre o rendimento da extração. Para as condições experimentais utilizadas no planejamento fatorial a razão sementes:solvente e a temperatura apresentaram efeito significativo $(\mathrm{p}<0,05)$, aumentando o valor destas variáveis aumenta-se o rendimento em óleo. O efeito da quantidade de solvente é claramente observado quando comparamos os resultados dos experimentos 5-7 e 10-12, já o efeito da temperatura é verificado ao observarmos os rendimentos obtidos nos experimentos 1-3 e 5-7. Goula (2013) reporta para a extração do óleo de Punica granatum L. a $50^{\circ} \mathrm{C}$ e 40 min que o aumento da razão semente:solvente de 1:4 a 1:20 aumento o rendimento em óleo de 35 para $42 \%$, respectivamente. A temperatura apresentou efeito significativo na extração do óleo de sementes de Isatis indigotica Fort para a faixa experimental de 30 a $60{ }^{\circ} \mathrm{C}$, conforme apresenta Li et al. (2012). 
Na faixa experimental avaliada, 20 a 60 min, o tempo de extração não apresentou efeito significativo no rendimento em óleo $(\mathrm{p}>0,05)$. Goula (2013) relatam que tempos superiores a 30 min não apresentam influencia no rendimento em óleo de Punica granatum L., efeito similar ao reportado por Tian et al. (2013).

Tabela 4 - Tabela de efeitos para as variáveis independentes na extração assistida por ultrassom do óleo de chia.

\begin{tabular}{|c|c|c|c|c|}
\hline Variável & Efeito & p-valor $^{\mathbf{a}}$ & Coeficiente & Erro padrão \\
\hline Média/intercepto & 23,82 & 0,00 & 23,82 & 0,110 \\
\hline Tempo - t (L) & 0,85 & 0,0507 & 0,429 & 0,135 \\
\hline Tempo - t (Q) & 2,60 & 0,00087 & 1,301 & 0,096 \\
\hline Temperatura - T (L) & 1,47 & 0,01229 & 0,737 & 0,135 \\
\hline Temperatura - T (Q) & 0,38 & 0,13812 & 0,193 & 0,096 \\
\hline Razão S:S - R (L) & 3,84 & 0,00076 & 1,923 & 0,135 \\
\hline Razão S:S - R (Q) & 1,43 & 0,00497 & 0,717 & 0,096 \\
\hline t x T & $-2,28$ & 0,00956 & $-1,140$ & 0,192 \\
\hline t x R & $-2,27$ & 0,00961 & $-1,138$ & 0,192 \\
\hline R x T & $-0,14$ & 0,73369 & $-0,071$ & 0,192 \\
\hline
\end{tabular}

a significância estatítistica $\mathrm{p}<0,05$.

A validade do modelo foi verificada pela análise do teste $\mathrm{F}$, mediante dados da análise ANOVA. O modelo é validado, ou seja, se ajusta satisfatoriamente aos dados experimentais quando $F_{\text {calc }}>F_{\text {tab. }} \mathrm{O}$ modelo obtido pela regressão linear (equação 1) explica $98,17 \%$ das variações entre os valores experimentais e os previstos pelo mesmo, indicando uma boa concordância, sendo que análise da estatística " $F$ " apresentou valores de Fcalc de 35,77 e Ftab de 3,06 .

$$
\begin{aligned}
& \text { Rendimento }(\%)=23,82+0,429 \times t+0,737 \times T+1,923 \times R+0,429 \times t^{2}+0,193 \times T^{2}+0,717 \times R^{2} \\
& -1,140 \times t \times T-1,138 \times t \times R-0,071 \times R \times T
\end{aligned}
$$

\subsection{Quantificação de ácidos graxos totais}

A composição dos ácidos graxos do óleo das sementes de chia obtido no experimento $12 \mathrm{e}$ por outros métodos de extração reportados na literatura é apresentada na Tabela 4. Em geral, os ácidos graxos podem ser classificados na seguinte ordem de abundância: ácido linolênico $>$ ácido linoléico $>$ ácido palmítico $>$ ácido oleico $>$ e ácido esteárico. Os resultados apresentados na Tabela 5 relatam distribuição semelhante entre os ácidos graxos do óleo de chia obtido neste estudo e a partir da extração por Soxhlet (n-hexano) e prensagem. Os principais componentes de óleos de diferentes métodos de extração foram o ácido linolênico $(\omega 3)$ e ácido linoleico $(\omega 6)$. Esses ácidos graxos são considerados essenciais (Hargrave et al., 2005; Glew et al.;, 2010), sendo que a relação $\omega 6: \omega 3$ do óleo obtido neste trabalho foi de 1:3,24. Segundo Guimarães et al. (2012) a determinação da relação $\omega 6: \omega 3$ é importante para a saúde humana já que o consumo excessivo de $\omega 6$, acompanhado pela diminuição da ingestão de $\omega 3$, é um fator de risco para doenças cardiovasculares. 
Ixtaina et al. (2011) relatam que a incorporação de sementes de chia na dieta seria benéfico, devido ao elevado teor de AGP presentes na sua composição (9,2\%). De acordo com Bowen et al. (2005) o consumo de óleos com elevados teores de AGPs pode fornecer benefícios a saúde, além de tornar o óleo mais estável). O óleo extraído das sementes de chia apresentou uma relação AGPI: AGS >11, considerado adequado para alimentos (Matsushita et al., 2010; Ramos-Filho et al., 2008; França et al., 2011). Dietas com relação AGPI: AGS <0,45 são considerados inadequados devido ao seu potencial para aumentar os níveis de colesterol no sangue.

Tabela 4 - Quantificação dos ácidos graxos em óleos de Chia obtidos em diferentes condições operacionais

\begin{tabular}{|c|c|c|c|c|}
\hline \multicolumn{2}{|c|}{ Método de Extração } & Ultrassom & Soxhlet & Prensagem \\
\hline \multicolumn{2}{|c|}{ Referência } & Este Trabalho & Ixtaina et al. (2011) & Martínez et al. (2012) \\
\hline Ácido Graxo ${ }^{1}$ & $\begin{array}{l}\text { Palmítico } \\
\text { Esteárico } \\
\text { Oleico } \\
\text { Linoleico } \\
\text { Linolênico }\end{array}$ & $\begin{array}{c}5,92 \pm 0,3 \\
1,94 \pm 05 \\
5,42 \pm 0,95 \\
20,44 \pm 0,7 \\
66,28 \pm 0,8\end{array}$ & $\begin{array}{c}6,2 \pm 0,4 \\
3,0 \pm 0,7 \\
5,3 \pm 1,1 \\
19,7 \pm 0,0 \\
65,6 \pm 0,8\end{array}$ & $\begin{array}{r}7,3 \pm 0,2 \\
2,8 \pm 0,2 \\
7,4 \pm 0,8 \\
22,0 \pm 0,1 \\
60,5 \pm 1,2\end{array}$ \\
\hline $\begin{array}{l}\text { AGS }^{2} \\
\text { AGPI }^{3} \\
\text { AGPI:AGS } \\
\omega 6: \omega 3\end{array}$ & & $\begin{array}{c}7,86 \\
86,72 \\
11,03 \\
1: 3,24\end{array}$ & $\begin{array}{c}9,2 \\
85,3 \\
9,27 \\
1: 3,32\end{array}$ & $\begin{array}{l}10,1 \\
82,5 \\
8,17 \\
1: 2,75\end{array}$ \\
\hline
\end{tabular}

\section{CONCLUSÕES}

Os efeitos das variáveis operacionais na extração assistida por ultrassom do óleo de chia é reportada e os resultados demonstram que os solventes: acetato de etila e $n$-hexano apresentaram melhor desempenho na extração do óleo. As variáveis razão sementes:solvente e temperatura apresentam maior influência no rendimento em óleo e o tempo de extração não apresentou efeito significativo. $\mathrm{O}$ maior rendimento em óleo foi obtido em $60^{\circ} \mathrm{C}, 40$ minutos de extração e razão sementes:solvente 1:12. O perfil de ácidos graxos do extrato é similar aos obtidos por outros métodos de extração e apresenta predominância do ácido linolênico.

\section{REFERÊNCIAS}

AYERZA, R. Oil content and fatty acid composition of chia (Salvia hispanica L.) from five northwestern locations in Argentina. J. Amer. Oil Chem. Soc., v. 72, p. 1079-1081, 1995.

AYERZA, R.; COATES, W. Influence of environment on growing period and yield, protein, oil and $\alpha$-linolenic content of three chia (Salvia hispanica L.) selections. Ind. C. Prod., v. 30, p. 321324, 2009.

BORNEO, R.; AGUIRRE, A.; LEÓN, A.E. Chia (Salvia hispânica L.) gel can be used as egg or oil replacer in cake formulations. J. Amer. Diet. Assoc., v. 110, p. 946-949, 2010. 
BOWEN, R.A.R.; CLANDININ, M.T. Maternal dietary 22:6n3 is more effective than 18:3n_3 in increasing content in phospholipids of glial cells from neonatal rat brain. Brit. J. Nutri., v. 93, p. 601-611, 2005.

CAPITANI, M.I.; SPOTORNO, V.; NOLASCO, S.M.; TOMÁS, M.C. Physicochemical and functional characterization of by-products from chia (Salvia hispanica L.) seeds of Argentina. LWT - F. Scien. Techn., v. 45, p. 94-102, 2012.

CÁRCEL, J.A.; PÉREZ, J. V. G.; BENEDITO, J.; MULET, A. Food process innovation through new technologies: Use of ultrasound. J. F. Engin., v. 110, p. 200-207, 2012.

CHEMAT, F.; HUMA, Z.; KHAN, M. K. Applications of ultrasound in food technology: Processing, preservation and extraction. Ultra. Sonochem., v. 18 p. 813-835, 2011.

DAUKSAS, E.; VENSKUTONIS, P.R.; SIVIK, B.; NILSON, T. Effect of fast $\mathrm{CO}_{2}$ pressure changes on the yield of lovage (Levisticum officinale Koch.) and celery (Apium graveolens L.) extracts. J. Superc. Fluids, v. 22, p. 201-210, 2002.

ESCLAPEZ, M. D.; PÉREZ, J.V.G.; MULET, A.; CÁRCEL, J.A. Ultrasound-assisted extraction of natural products. .F. Engin. Rev., v. 3, p.108-120, 2011.

FRANÇA, P. B.; AGUIAR, A. C.; MONTANHER, P. F.; BOROSKI, M.; SOUZA, N. E.; VISENTAINER, J. V. Incorporation and fatty acid composition in liver of Nile tilapia fed with flaxseed oil. Acta Scient. Techn., v. 33, p. 221-225, 2011.

GLEW, R. H.; KRAMER, J. K.; HERNANDEZ, M.; PASTUSZYN, A.; ERNST, J.; DJOMDI, N. N.; VANDERJAGT, D. J. The amino acid, mineral and fatty acid content of three species of human plant foods in Cameroun. Food, v. 4, p. 1-6, 2010.

GOULA, A.M. Ultrasound-assisted extraction of pomegranate seed oil - Kinetic modeling. J. Food Engin., v.117, p.492-498, 2013.

GUIMARÃES, R. C. A.; MACEDO, M. L. R.; MUNHOZ, C. L.; FILIU, W.; VIANA, L. H.; NOZAKI, V. T.; HIANE, P. A. Sesame and flaxseed oil: nutritional quality and effects on serum lipids and glucose in rats. F. Scien. Techn., v. 33, p. 209-217, 2012.

HARGRAVE, K. M.; AZAIN, M. J.; MINER, J. L. Dietary coconut oil increases conjugated linoleic acid-induced body fat loss in mice independent of essential fatty acid deficiency. Biochim. Biophys. Acta, v. 1737, p. 52-60, 2005.

IAL - INSTITUTO ADOLFO LUTZ. Métodos físico-químicos para análise de alimentos. São Paulo, 2008.

IXTAINA, V.Y.; MARTÍNEZ, M.L.; SPOTORNO, V.; MATEO, C.M.; MAESTRI, D.M.; DIEHL, B.W.K.; NOLASCO, S.M.; TOMÁS, M. C. Characterization of chia seed oils obtained by pressing and solvent extraction. J. F. Comp. Anal., v. 24, p. 166-174, 2011.

LI, T., QU, X., ZHANG, Q., WANG, Z. Ultrasound-assisted extraction and profile characteristics of seed oil from Isatis indigotica Fort. Ind. C. Prod., v. 35, p. 98-104, 2012.

MARTÍNEZ, M.L.; MARÍN, M.A.; FALLER, C.M.S.; REVOL, J.; PENCI, M.C.; RIBOTTA, P. D. Chia (Salvia hispanica L.) oil extraction: Study of processing parameters. LWT - F. Scien. Techn., v. 47, p. 78-82, 2012.

MARUYAMA, S.A.; PALOMBINI, S.V.; CLAUS, T.; CARBONERA, F.; MONTANHER, P.F.; SOUZA, N.E.; VISENTAINER, J.V.; GOMES, S.T.M.; MATSUSHITA, M. Application of box- 
behnken design to the study of fatty acids and antioxidant activity from enriched white bread. $J$. Braz. Chem. Soc., v. 24, p. 1520-1529, 2013.

MATSUSHITA, M.; MARTINS JÚNIOR, A. C.; GOMES, S. T. M.; MACEDO, F. A. F.; VISENTAINER, J. V.; SOUZA, N. E. Influence of slaughter weight on the proximate composition and fatty acid profile of feedlot-fattened lamb meat. Acta Scien. Techn., v. 32, p. 315$318,2010$.

OLIVEIRA, R.C.; BARROS, S.T.D.; GIMENES, M.L. The extraction of passion fruit oil with green solventes. J.Food Eng., v. 117, pp.458-463, 2013.

PATIST, A.; BATES, D. Ultrasonic innovations in the food industry: From the laboratory to commercial production. Innov. F. Scien. Emerg. Technol., v.9, p.147-154, 2008.

PIZARRO, P.L.; ALMEIDA, E.L.; SAMMÁN, N.C.; CHANG, Y.K. Evaluation of whole chia (Salvia hispânica L.) flour and hydrogenated vegetable fat in pound cake. F. Scien. Techn., v.54, p.73-79, 2013.

PRADO, A. G. S. Química Verde, Os Desafios da Química do Novo Milênio. Quím. Nova, v.26, p.738-744, 2003.

RAMOS-FILHO, M. M.; RAMOS, M. I. L.; HIANE, P. A.; SOUZA, E. M. T. Lipid profile of four species of fish from the pantanal region of Mato Grosso do Sul. Ciênc. Tecn. de Alim., v. 28, p. 361-365, 2008.

TIAN, Y.; XU, Z.; ZHENG, B.; LO, Y.M. Optimization of ultrasonic-assisted extraction of pomegranate (Punica granatum L.) seed oil. Ultra. Sonochem., v. 20, p. 202-208, 2013.

VILKHU, K.; MAWSON, R.; SIMONS, L.; BATES, D. Applications and opportunities for ultrasound assisted extraction in the food industry-A review. Innov. F. Scien. Emerg. Technol., v. 9, p. 161-169, 2008.

WALKER, R. E. Official methods and recommended practices of the American Oil Chemists' Society (Method AOCS Ce 2-66). Champaign: American Oil Chemists Society, 1990.

WORLD HEALTH ORGANIZATION. Joint Consultation: fats and oils in human nutrition. Nutri. Rev., v. 53, p. 202-205, 1995. 